Research Article

\title{
Microseismic Monitoring of Energy Changes in Deep Tunnels during the TBM Tunneling of the Jinping II Hydropower Station
}

\author{
Duanyang Zhuang $\mathbb{D}^{1,2}$ Ke Ma $\mathbb{D}^{1,2}$ Chunan Tang, ${ }^{1,2}$ Zhengzhao Liang, \\ and Zhenwei Wang 3 \\ ${ }^{1}$ State Key Laboratory of Coastal and Offshore Engineering, Dalian University of Technology, Dalian 116024, China \\ ${ }^{2}$ Institute of Rock Instability and Seismicity Research, Dalian University of Technology, Dalian 116024, China \\ ${ }^{3}$ Mine Safety Technology Branch, China Coal Research Institute, Beijing 100013, China
}

Correspondence should be addressed to Ke Ma; mmaarrkk1983@163.com

Received 9 April 2018; Accepted 30 May 2018; Published 18 July 2018

Academic Editor: Fengqiang Gong

Copyright (c) 2018 Duanyang Zhuang et al. This is an open access article distributed under the Creative Commons Attribution License, which permits unrestricted use, distribution, and reproduction in any medium, provided the original work is properly cited.

\begin{abstract}
The TBM tunneling at the Jinping II hydropower station in Southwest China has received extensive concerns around the world because of its large engineering scale and the high rockburst risks faced in the tunnel advancement. The associated energy changes of rockbursts and control method for safe TBM tunneling are to be further investigated. A movable microseismic (MS) monitoring system was established to capture the MS events and rockbursts when the TBM excavated the headrace tunnel \#1 at the Jinping II hydropower station. The spatial and temporal patterns of the energy changes in the tunnel rock masses were studied. Meanwhile, the evolution of a rockburst encountered in front of the TBM excavation face was revealed, and the performance of the top pilot tunnel method on the reduction of the rockburst risks in the headrace tunnel \#1 was evaluated based on the energy changes of the surrounding rock masses. It can be concluded that energy accumulation and energy release firstly occurred in the surrounding rock masses at the southern end of the top pilot tunnel section of the headrace tunnel \#1. Then, energy transference of the rock masses took place from the southern end to northwest of the top pilot tunnel giving rise to the occurrence of a moderate rockburst about $30 \mathrm{~m}$ in front of the tunnel. However, no rockbursts appeared when the TBM excavated through the top pilot tunnel section of the headrace tunnel \#1. Therefore, the top pilot tunnel method really works in reducing the risks of rockbursts during the TBM tunneling in deep tunnels.
\end{abstract}

\section{Introduction}

A mass of hydropower stations have been constructed in order to meet the growing energy needs around the world in which most of them are located in mountains and canyons featured by complicated terrain with deep valleys possessing a rich water resource [1-3]. The Jinping II hydropower station, one of the most complicated hydropower stations, has seven deepburied parallel $16.7 \mathrm{~km}$ long tunnels, which traverses Jinping Mountain in Southwest China. The depth of the tunnel sections is generally greater than $1,500 \mathrm{~m}$ with a maximum of $2,525 \mathrm{~m}$, resulting in high geostress in the tunnels $[4,5]$. The development of tunnel boring machine (TBM) in the last half century has promoted it to become one of the main choices for the excavation of these long, large, and deep tunnels since it has the advantages of high efficiency, rapid construction, good quality and safety [6]. Therefore, two $12.4 \mathrm{~m}$ diameter TBMs have been specially designed and constructed to excavate part of two Jinping II headrace tunnels and drainage tunnel, which is the most complex tunnel group worldwide [7].

Rockbursts are engineering disasters normally induced by the excavation of the deep-buried tunnels with highstress, hard, brittle rock zones [8, 9]. During the tunneling of the headrace tunnels at the Jinping II hydropower station, a large amount of intense rockbursts occurred not only causing casualties and equipment troubles, but also resulting 
in many problems like project delays [10]. As is well known, rockbursts have extremely complicated evolution mechanisms [11-13]. A series of studies concerning the evolution mechanisms of rockbursts in the deep-buried tunnels have been carried out for decades in many countries [14-16]. Tan [17] found that a rockburst would be encountered when the rock debris is ejected. Xie and Pariseau [18] studied the associated microseismicity of rockbursts by using fractal geometry and damage mechanics and pointed out that the lowest fractal dimension is generally produced near the occurrence of a rockburst. By introducing case records, Ortlepp and Stacey [19] made significant progress in the knowledge of rockbursts and pointed out that strainbursts mainly occur. Zhang and Fu [20] reviewed the back information of cases histories, research methodologies, and classification of rockbursts commonly used in China and abroad. Feng et al. [21] focuses on the evolution processes of different types of rockbursts occurring in deep tunnels excavated by different excavation methods. Cai [22] summarized the classification and corresponding characteristics of the rockbursts and presented seven principles for the right design of the rock support design in burst-prone ground. Fan et al. [23] summarized the recent researches and engineering practice, including the influence factors, evolution laws, and physical mechanisms of strain rockbursts. Chen et al. $[24,25]$ investigated the effect of high temperature on the rockburst proneness of rocks and found that the degree of rockburst is increasing with rising temperature, which is important to understand the mechanism of rockbursts in deep-buried tunnels at high ground temperature. Great achievements have been made, which help understand the evolution processes and occurrence mechanisms of rockbursts.

A great deal of research suggests that energy accumulation and dissipation always occur during the excavation of deep tunnels, and these violent energy changes may cause microseismic (MS) events in the tunnel rock masses [26-30]. The characteristics of MS events and the energy changes they reflect during excavation are of great importance to understand the evolution process of rockbursts and evaluate the risks of rockbursts in deep tunnel engineering. Recently, the MS monitoring technique has gradually been adopted to monitor the construction of deep-buried tunnels [31]. Tang et al. [32] firstly applied Canadian ESG MS monitoring system to monitor the evolutions of rockbursts in the excavation of the Jinping II long tunnels. The feasibility in principle of monitoring and prediction of rockbursts was discussed. Lu et al. [33] revealed the frequency-spectrum evolutionary rule of MS signals before and after roof fall to evaluate rockburst danger. Chen et al. [34] selected the radiated energy obtained by MS monitoring as an index for the intensity evaluation of rockbursts and put forward a new set of criteria to classify the rockburst intensity quantitatively by utilizing the radiated energy and surrounding rock damage severity. Ma et al. [35] investigated the spatial and temporal evolution of the associated MS activities along with the rockbursts which was encountered at the Jinping II hydropower station through the parameter of MS event density. Using cumulative number and cumulative energy of MS events, Feng et al. [36] studied the MS time-sequences accompanying rockburst development processes at the Jinping deep-buried tunnels. Xiao et al. [37] determined the rockburst evolution mechanisms by identifying the modes of rock fractures involved in the Jinping rockburst using a newly proposed comprehensive method based on the comparison of the energy ratio method, the moment tensor analysis, and the method of P-wave development. All these studies mentioned above have not only promoted the development of MS monitoring technique in tunneling, but also significantly enhanced the evolution mechanism identification of rockbursts in deep-buried tunnels. The indices concerning MS monitoring, including MS event density, cumulative MS energy, MS apparent volume, frequency-spectrum characteristics, and MS source mechanism, have been proposed and widely used to analyze the evolution processes of rockbursts. Although MS energy has frequently been adopted in the parameter analysis of rockbursts in deep-buried tunnel, few studies focused on the spatial evolution of MS energy changes of the surrounding rock masses, which is crucial to capture the precursory information of rockbursts. Meanwhile, excavation methods implemented in deep-buried tunnel excavation have considerable influence on the rockburst evolution process. Most deep-buried tunnels have been excavated by drill-and-blast (D\&B) method resulting in large amounts of studies on the evolution mechanism and prevention of rockbursts associated with blasting excavation [38-42]. Nevertheless, TBM has always been the preferred method to construct the deep-buried tunnels owing to its incomparable advantages. Therefore, the evolution processes of rockbursts induced by the TBM excavation and the safety control method for the TBM excavation through deep tunnels with high risk of rockburst need to be further studied in order to boost the automation and disaster prevention of deep-buried tunneling.

To better understand the energy changes in deep tunnels during TBM tunneling, the current study took the headrace tunnel \#1 at the Jinping II hydropower station when the TBM passed through the top pilot tunnel section as a case study. A scenario of movable MS monitoring system was specially designed to capture the associated MS events in real-time during the TBM tunneling. The spatial patterns of MS events and energy changes together with the evolution process of a rockburst that was encountered in the headrace tunnel \#1 were investigated. The effectiveness of the top pilot tunnel method on reducing the rockburst risks in the headrace tunnel \#1 was assessed.

The remaining paper is organized as follows: project backgrounds including engineering geology features and rockburst characteristics are introduced in Section 2; the design for the TBM tunneling of the headrace tunnel \#1 is described in Section 3; the establishment of MS monitoring system is performed in Section 4; in Section 5, MS monitoring results and discussions are obtained; and in the end, conclusions are drawn in Section 6.

\section{Project Background}

2.1. Overview. Located in Sichuan Province, Southwest China (Figure 1), the Jinping II hydropower station utilizes the natural head fall of the Jinping Bend on the Yalong River, 


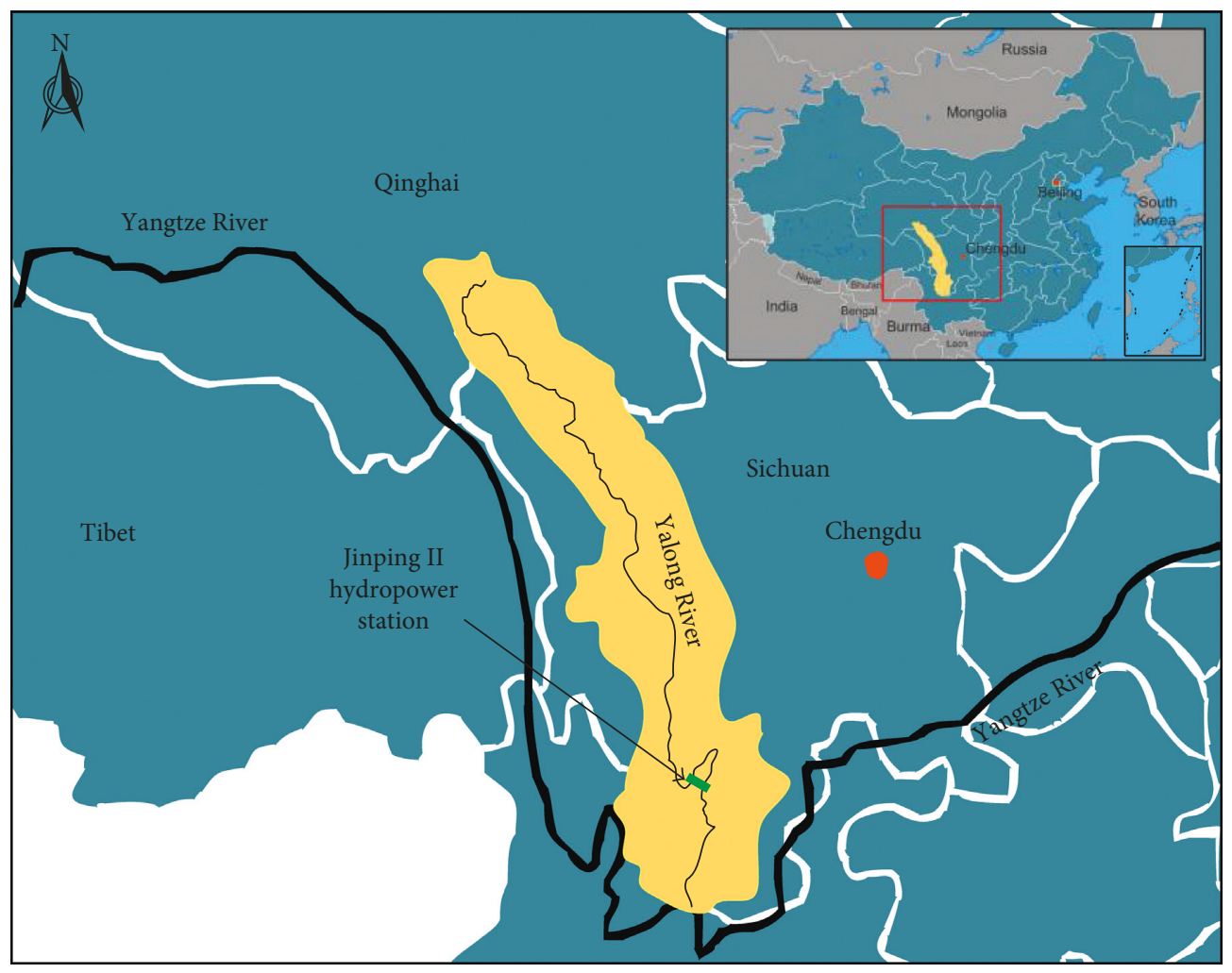

FIgURE 1: Location of the Jinping II hydropower station.

where several tunnels were constructed for power generation. It is an important cascade hydropower station on the Yalong River, in which the total capacity is $4,800 \mathrm{MW}$. Seven parallel tunnels were excavated, including the headrace tunnels \#1-\#4, the drainage tunnel, and the auxiliary access tunnels A and B (Figure 2). The headrace tunnels cross over the Jinping Mountain in a parallel layout. The azimuth of the major axis is $\mathrm{N} 58^{\circ} \mathrm{W}$. The slope is gentle with a gradient of $3.65 \%$ at the slope toe. The cover depths of the tunnels generally range from $1,500 \mathrm{~m}$ to $2,000 \mathrm{~m}$ with a maximal depth of about 2,525 $\mathrm{m}$ [43]. The headrace tunnel sections with cover depth over $1,500 \mathrm{~m}$ account for $75.8 \%$ of the total tunnel length, resulting in most tunnels being subjected to high stress. The average length of the tunnel is about $16.7 \mathrm{~km}$ and the tunnel diameters of headrace tunnels \#1 and \#3, \#2 and $\# 4$ are $12.4 \mathrm{~m}$ and $13 \mathrm{~m}$, respectively. The center-tocenter distances between the four headrace tunnels are $60 \mathrm{~m}$. TBMs were adopted to excavate the headrace tunnels \#1 and $\# 3$, and the D\&B method was used to excavate the other two headrace tunnels [4]. The excavation of the headrace tunnels started in early February 2007, and all the tunnels have been completed and the power unit at the Jinping II hydropower station successfully generated electricity since December 30, 2012.

2.2. Characteristics of Engineering Geology. Jinping Mountain is located in the geomorphological ladder of the transition zone between the Tibetan Plateau and the Sichuan Basin. It extends in a nearly N-S direction, as shown in Figure 2. The headrace tunnels laid in Jinping Mountain pass through a set of strata from Devonian to Jurassic, of which marble lithology accounts for $70-80 \%$, as shown in Figure 3. The strata along the headrace tunnel \#1 are mainly Triassic strata and the main lithology in the research area is the Baishan marble (T2b). The rock masses along the headrace tunnel \#1 alignment are mainly Class III and Class II rock masses, accounting for $53.5 \%$ and $37.5 \%$, respectively. Class IV rock masses account for $2.7 \%$. The rock quality is generally good. Besides, some faults are developed along the headrace tunnel \#1. The faults can be classified into four tectonic groups according to their trace and extension direction, namely, NNE, NNW, NE NEE, NW NWW (mainly with steep slope angles) oriented faults, among which the tensile and torsional faults in approximately EW and NNE directions are well developed. The site suffers from extremely high geostress. At a depth of $2,525 \mathrm{~m}$, the gravitational stress is 69.94 MPa. Moreover, locating in Southwest China, the headrace tunnel \#1 experience significant tectonic loadings [44]. According to the back analysis and regression of the three-dimensional initial stress field based on the field stress measurement results, the major principal stress is $70.1 \mathrm{MPa}$ and the minor principal stress is $30.1 \mathrm{MPa}$ at an elevation of $1,600 \mathrm{~m}$. The principal stresses in rock masses within the fault zones are obviously reduced, indicating that the faults influence the field stress distribution significantly [32].

2.3. Rockburst Characteristic Analysis. During the excavation of seven parallel tunnels at the Jinping II hydropower station, a number of rockbursts were encountered. The rockburst intensity varied from mild rockbursts in the shallow-buried 


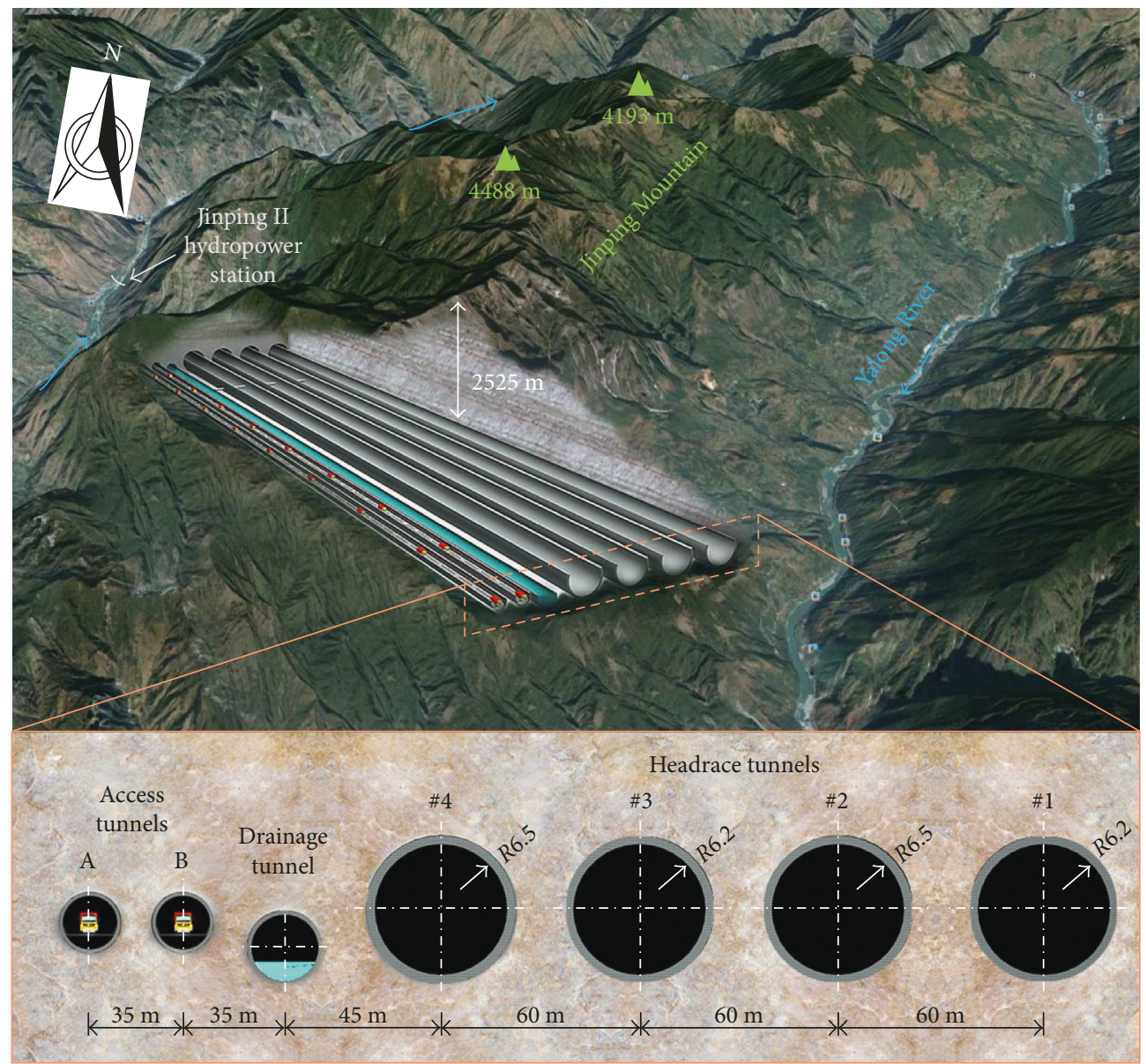

FIGURE 2: Layout of the Jinping II hydropower station.

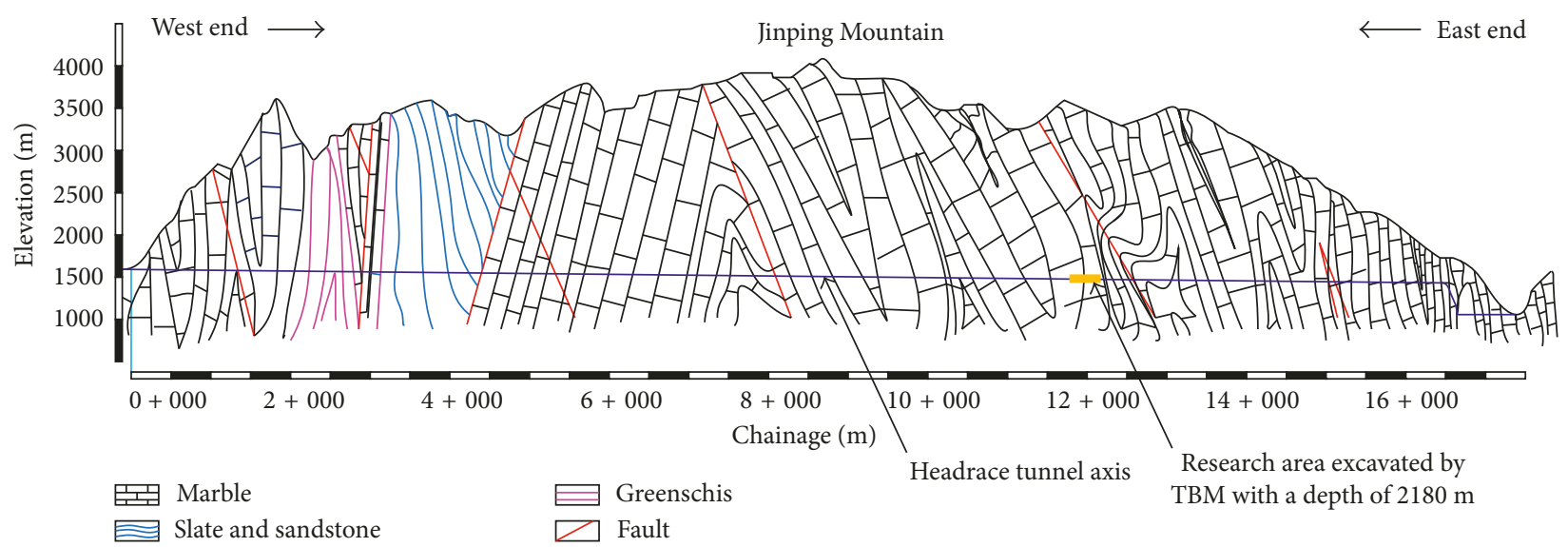

FIgURE 3: Geomorphic map along the headrace tunnels of the Jinping II hydropower station.

condition to extremely strong rockbursts in the deep-buried condition with considerable frequency. The detailed records of rockburst events occurred in four headrace tunnels between 3 October 2010 and 21 November 2011 are shown in Table 1 [45]. From chainage $4+000 \mathrm{~m}$ to chainage 12 $+000 \mathrm{~m}, 71$ rockbursts happened in the headrace tunnel \#1, with accumulated length of $986 \mathrm{~m}$, accounting for $12.3 \%$ of the statistical section, among which the number of strong rockburst is 9. Contrastively, other headrace tunnels suffered from more strong rockbursts during the excavation. Worse still, according to incomplete statistics, the occurrence of rockburst along the drainage tunnel is serious. From chainage $1+155 \mathrm{~m}$ to chainage $9+500 \mathrm{~m}$ at the western end of the drainage tunnel, the tunnel length is $8.3 \mathrm{~km}$ and the 
TABLE 1: Rockburst in the headrace tunnels at chainage $4+000-12+000 \mathrm{~m} \mathrm{[45].}$

\begin{tabular}{lccc}
\hline Tunnel & Number of rockbursts & Accumulated length $(\mathrm{m})$ & Number of strong rockbursts \\
\hline Headrace tunnel \#1 & 71 & 986.0 & 9 \\
Headrace tunnel \#2 & 85 & 8868.0 & 10 \\
Headrace tunnel \#3 & 186 & 1508.1 & 24 \\
Headrace tunnel \#4 & 145 & 961.2 & 18 \\
Total & 487 & 12323.3 & 61 \\
\hline
\end{tabular}

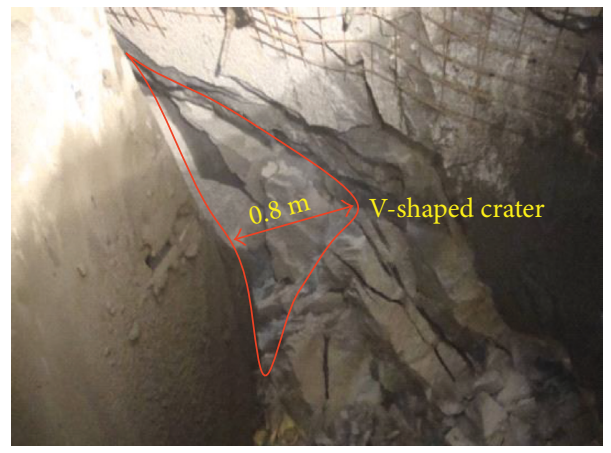

(a)

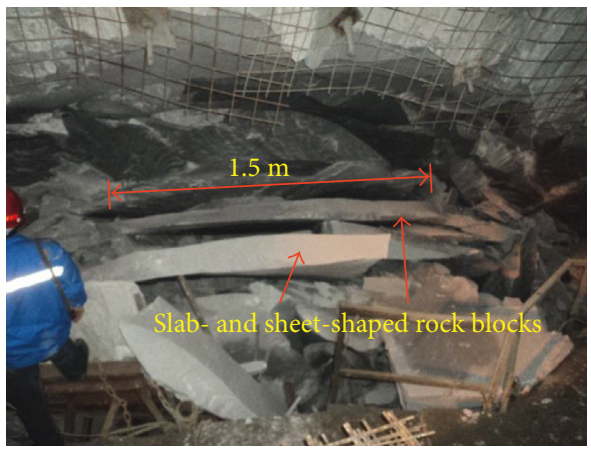

(b)

FIGURE 4: On-site photos of rock failures caused by rockbursts. (a) V-shaped crater caused by a rockburst. (b) Slab- and sheet-shaped rock blocks ejected from the wall in the drainage tunnel.

accumulated length for tunnel sections with rockburst events is $2158 \mathrm{~m}$, accounting for $26 \%$ of the tunnel length. From chainage $9+725 \mathrm{~m}$ to chainage $16+410 \mathrm{~m}$ at the eastern end, the tunnel length is $6.7 \mathrm{~km}$ and the accumulated length for tunnel sections with rockburst events is $955.3 \mathrm{~m}$, accounting for $14.3 \%$ of the tunnel length.

Rockbursts typically occurred in the tunnel sidewalls which were accompanied by a sudden cracking sound or clunk in the deep tunnel. In regard to the deep tunnels excavated by TBMs at the Jinping II hydropower station, the primary rockbursts mostly happened inside the cutter head of the TBM, and the secondary rockbursts were encountered a few hours after the TBM passed between the cutter head and gripper shoe of the TBM, which is about $20 \mathrm{~m}$ away from the excavation face. Normally, the primary rockbursts were relatively mild, while the secondary rockbursts were extremely intense and devastating. For example, when the TBM advanced to a depth of 1,500 $\mathrm{m}$ in the drainage tunnel, successive rockbursts were encountered for a tunnel section that is $30 \mathrm{~m}$ long. The rock spalling mainly occurred at the right spandrel and the left arch springing where $\mathrm{V}$-shaped craters were developed with a depth of 0.6 to $1 \mathrm{~m}$ shown in Figure 4(a). In the meantime, slab- and sheet-shaped rock blocks ejected from the roof and sidewall were found frequently in the drainage tunnel and the largest ejected plate reached $1.5 \mathrm{~m}$ long and $1.2 \mathrm{~m}$ wide seen in Figure 4(b). Rockbursts with various intensities severely disturbed the normal operation of TBM and affected the advance rate and tunneling performance of TBM. In view of the high risk and huge damage of the strong rockbursts encountered during TBM tunneling, it is necessary to analyze the influence of TBM excavation on rockburst evolution and propose effective preconditioning method to reduce the risk of potential rockbursts in the large scale deep-buried tunnels.

\section{Design for the Excavation of the Headrace Tunnel \#1}

3.1. Technical Specifications of the TBM. The headrace tunnel \#1, 12.4 $\mathrm{m}$ in diameter, was excavated using a TBM designed by Robbins Co., Ltd. The open-type TBM has a flat-face cutter head shown in Figure 5. The cutters have a diameter of $48.26 \mathrm{~cm}$, which have relatively high breakage efficiency and high abrasive resistance. The spacing of central cutters is about $100 \mathrm{~mm}$ and that of panel cutters is $86.5 \mathrm{~mm}$, which are commonly adopted cutter spacing. The maximum rotational speed is $5.6 \mathrm{rpm}$ and the rated torque is $16519 \mathrm{KN} \cdot \mathrm{m}$. The maximum allowable thrust and recommend thrust force are $24,260 \mathrm{KN}$ and $22,703 \mathrm{KN}$, respectively. Certainly, the TBM has a super power of 4,410 KW [46]. The TBM support system consists of four zones, namely, Zone L1, Zone L2, Zone L3, and Zone L (Figure 6). Zone L1 is the emergency safety support zone, where rock bolt, steel mesh, steel frame, steel tile, and shotcrete can be installed or sprayed. Zone L2 is the main support zone, where rock bolt and shotcrete can be installed or sprayed. Zone L3 is the reinforced support zone, where shotcrete can be sprayed and Zone L is an extrazone for supplement support and other purposes. More detailed specifications of the support system of the TBM can be found in related references $[47,48]$.

3.2. Excavation Scheme. Several extremely strong rockbursts have been encountered during the construction of the 


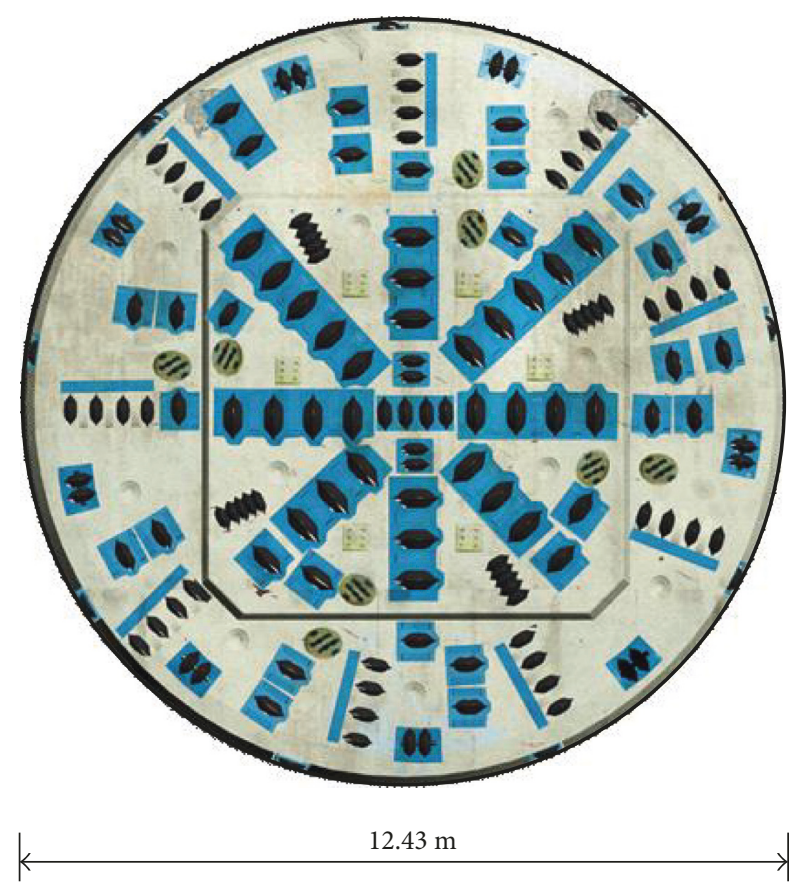

FIGURE 5: The cutter head of the TBM used for the headrace tunnel \#1.

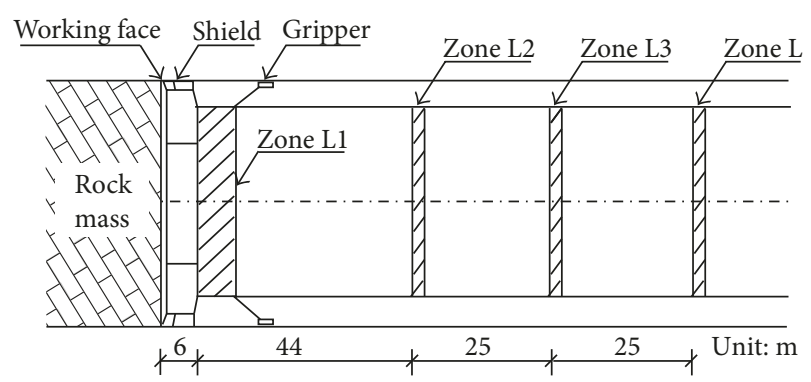

FIgURE 6: Layout of the support system in the TBM.

Jinping II hydropower station before May 2010, and the rockburst occurred on the left spandrel of the drainage tunnel from chainage $9+283 \mathrm{~m}$ to chainage $9+322 \mathrm{~m}$ on November 28, 2009 was the most intense. The "11.28" rockburst destroyed the original supports of the tunnel and caused a failure zone around the axis of the tunnel with a radius of $30 \mathrm{~m}$. The rockburst also broke the main beam and duty room of the TBM [43]. Since then, the top pilot tunnel method was proposed to reduce the risk of rockbursts in the headrace tunnels. The key points of this method are as follows: (i) excavating the top pilot tunnel by the D\&B method and reducing the risk of rockbursts as much as possible at the same time; (ii) minimizing the risk of rockbursts when excavating the remaining tunnel by the TBM; and (iii) making the TBM work in its maximum capacity [48].

For the excavation of the headrace tunnel \#1 from chainage $11+976 \mathrm{~m}$ to chainage $12+125 \mathrm{~m}$ where the tunnel was prone to strong rockburst, the top pilot tunnel method was implemented. The cross section of the top pilot tunnel is displayed in Figure 7 and the excavation scheme is presented

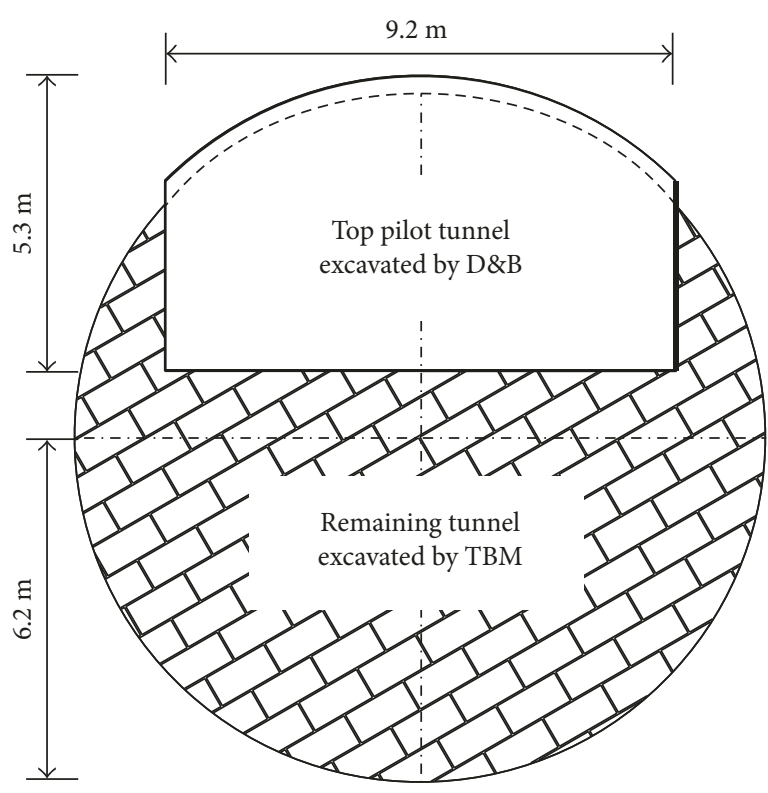

Figure 7: The cross section of the top pilot tunnel.

in Figure 8. The top pilot tunnel is city-gate shaped with a height of $5.3 \mathrm{~m}$ and a width of $9.2 \mathrm{~m}$. Because the working face of the headrace tunnel \#2 excavated by the D\&B method was remarkably prior to that of the headrace tunnel \#1, it is possible to excavate a transverse branch tunnel at chainage $11+976 \mathrm{~m}$ serving as the access tunnel. Then, drilling and blasting were employed to excavate the top pilot tunnel and the primary support was carried out. At last, the TBM advanced through the top pilot tunnel by excavating the remaining portion of headrace tunnel \#1, and the initial support was completed by implementing systematic support. It is noteworthy that overexcavation is required at the top arch of the top pilot tunnel to make the rock bolts at the top arch covered completely by the shotcrete and protect the roof shield of the TBM [48]. In the excavation scheme of the headrace tunnel \#1, the geological radar was applied to explore the geological conditions in front of the working face. The top pilot tunnel was completed on May 21, 2010 and the remaining tunnel began to be excavated by the TBM from southeast to northwest.

\section{Establishment of the MS Monitoring System}

4.1. Configuration of the MS Monitoring System. A movable integrated system for MS monitoring and early warning of rockbursts, which can adjust the sensor locations with TBM advancing, was established. The integrated monitoring and early warning system consisted of sensors, an embedded MS monitoring system in the TBM, and Dalian Center in Northeast China for analyzing and early warning. The sensors are uniaxial accelerometers with an acquisition frequency range of $50 \mathrm{~Hz}-5 \mathrm{kHz}$ and a sensitivity of $30 \mathrm{~V} / \mathrm{g}$. The MS monitoring system installed in the TBM was manufactured by ESG (Engineering Seismology Group Canada Inc.). Specifically, it was composed of (i) a concentrator connected with all accelerometers to collect the MS signals in real-time via shield 


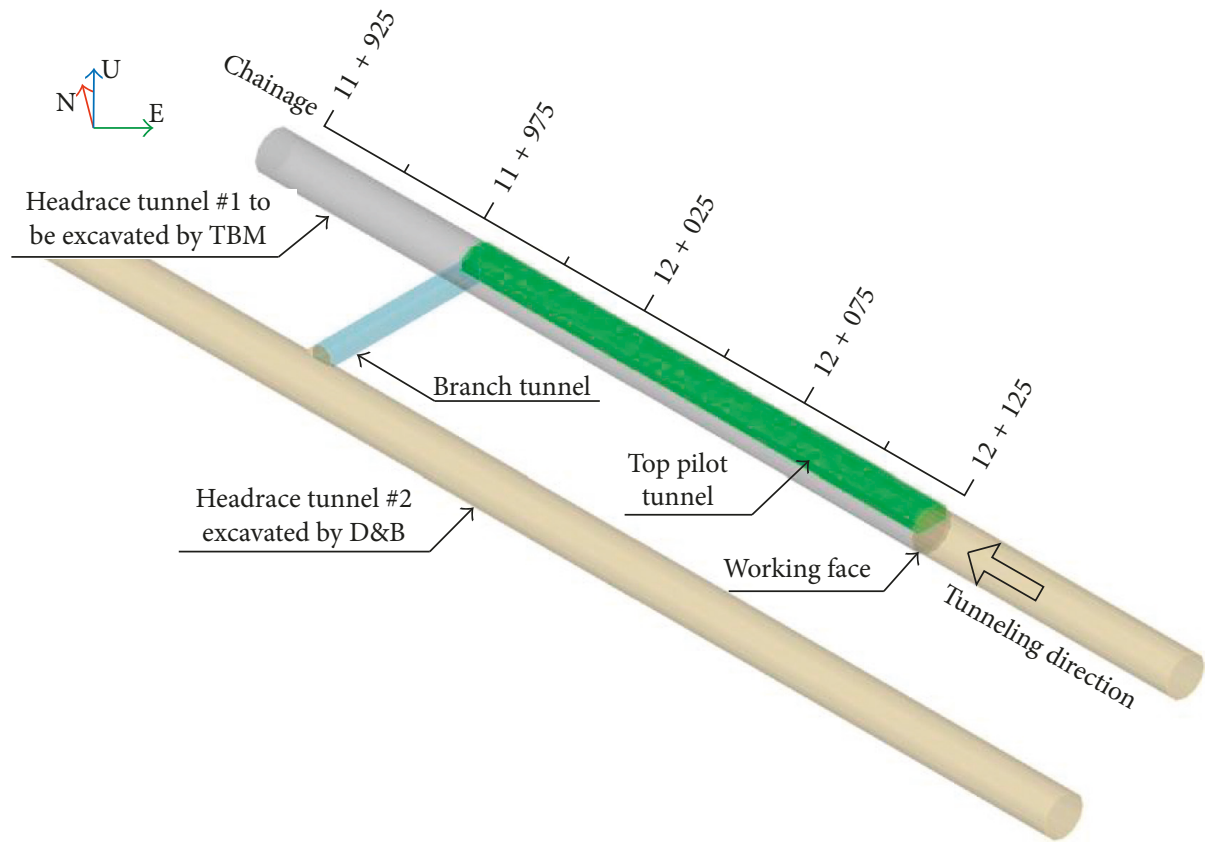

FIgURE 8: The scheme for the excavation of the headrace tunnel \#1.

cables minimizing the influences of the outer electromagnetic field on the data communication; (ii) a 24-bit analog-to-digital converter with a sampling frequency of $10,000 \mathrm{~Hz}$ making the received analog electrical signals be converted into digital signals; (iii) a hard disk used to store the original raw data and the converted digital data; (iv) a processor equipped with corresponding processing software which is able to filter noises, identify signals, locate MS events, and calculate MS source parameters automatically and manually; and (v) a central computer in site configured to visualize MS monitoring results with a $3 \mathrm{D}$ visualization software and a wireless data transfer unit for the remote wireless transmission. The analysis and early warning center in Dalian was connected to the MS monitoring system in site by the specially designed wireless network. MS spatial distribution and energy changes during the TBM tunneling were analyzed in Dalian Center. When the rockburst threshold is triggered, the early warning would be sent out from the chief engineer office to the in-site office. Besides, the integrated monitoring and early warning system has some software such as the digital signal acquisition software in the converter, the data processing software in the processor and the 3D visualization software, MMS-View, based on remote wireless transmission.

4.2. Sensor Array and Source Location. According to the geological conditions and construction features of the headrace tunnel, a sensor network of 6 accelerometers was adopted. In the monitoring practices, the working face keeps changing with the advancement of the TBM. Thus, two alternative sensor arrays were proposed to realize the movable monitoring of MS events and rockbursts during the TBM tunneling of the headrace tunnel \#1. The layout schemes of the two sensor arrays, called the following sensor array and the neighbour sensor array, are shown in Figure 10 and the descriptions are as follows: (i) The following sensor array: As shown in Figure 9, the embedded MS monitoring system can automatically move with TBM advancing. 6 accelerometers follow the TBM working face depicted in Figure 10(a). All the accelerometers are located at 3 sections, namely, Zone L2, Zone L3, and Zone L in Figure 6. The sensors are distributed in array at the spandrel of the south and north sidewalls. Two of them are arranged at the section of Zone L2 which about $50 \mathrm{~m}$ behind the working face and the other four sensors are installed in the sections of Zone L3 and Zone L. Regularly, the spacing between sensor sections is $25 \mathrm{~m}$. When TBM advanced by about $25 \mathrm{~m}$, the two sensors at the section of former Zone L are about $125 \mathrm{~m}$ away from the away from the excavation face. These two sensors need to be retrieved and reinstalled at the section of new Zone L2 that is $50 \mathrm{~m}$ away from the excavation face. In order to avoid cable breakage or sensor damage, and ensure continuous data acquisition, enough cable has to be reserved for the TBM advancement. Notice that, during the installation of microseismic sensors, a plug is inserted to the borehole before shotcreting and then the plug is removed to install the sensor after shotcreting. Generally, the other devices like concentrator, A/D converter, hard disk, and processor are arranged at Zone L. Thus, the automatic adjustment of embedded MS monitoring system is realized with the advancement of TBM. Figure 10(b) presents the location mode of the following sensor array. The propagation directions of MS waves generated by microcracking are almost the same leading to a tangent orientation mode which was discussed by Xu et al. [49]. It is clearly found that the source location errors perpendicular to the tunnel 


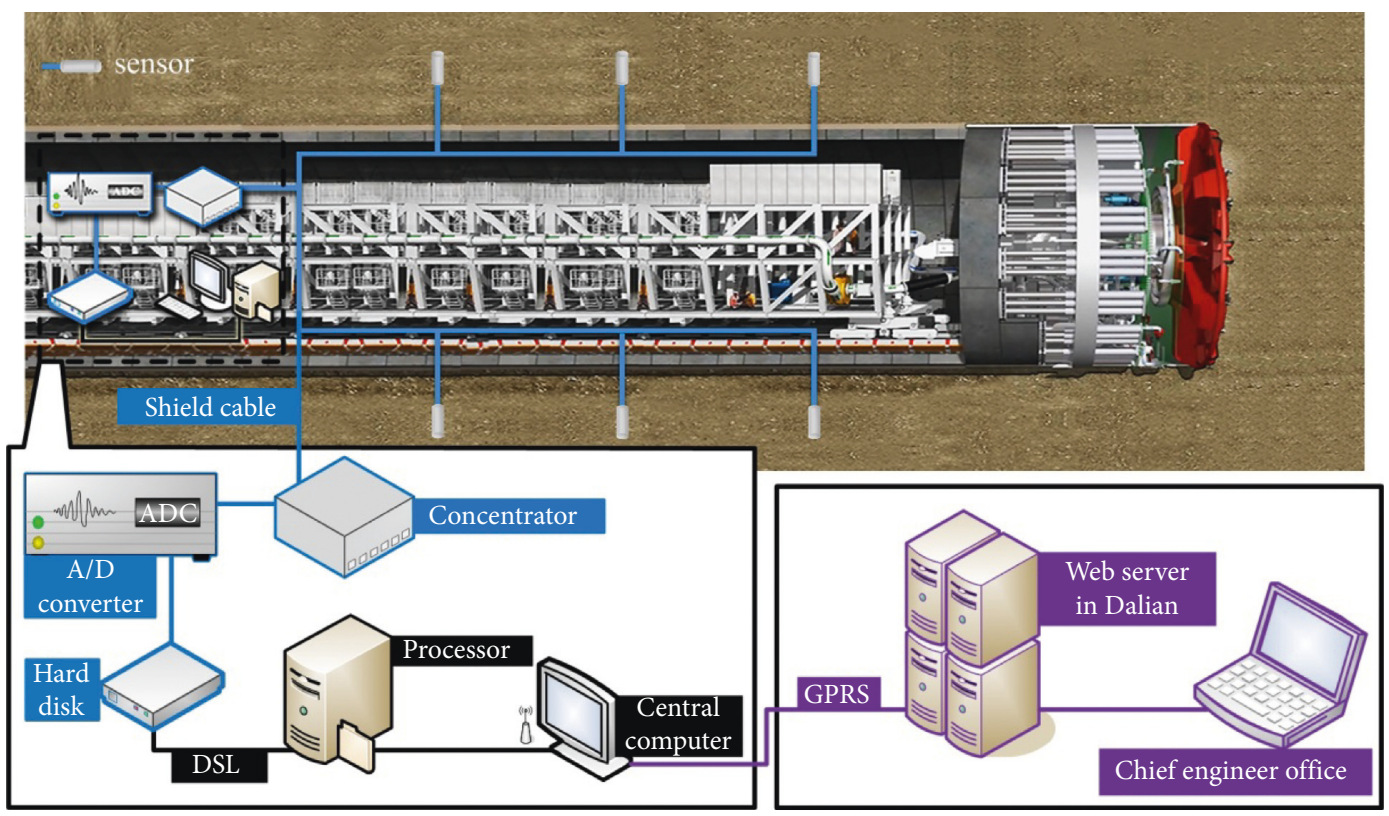

Embedded MS monitoring system

Analysis and early warning center in Dalian

FIgURE 9: Topological graph of a movable integrated system for MS monitoring and early warning of rockbursts during TBM tunneling.

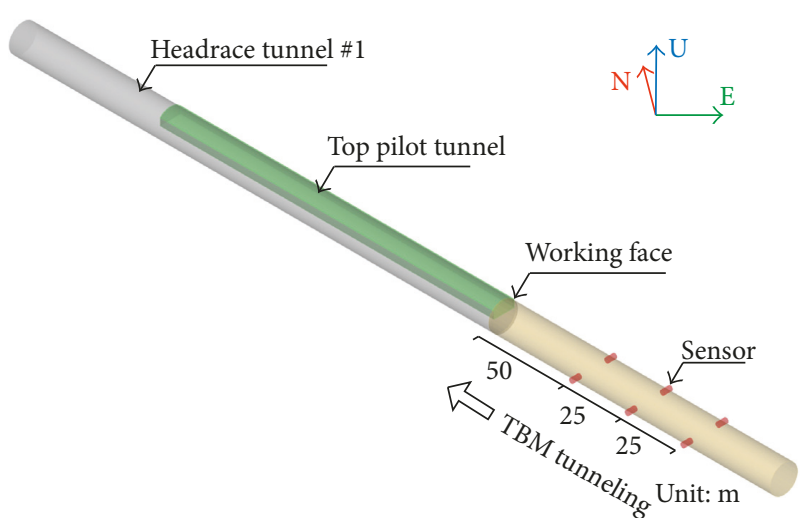

(a)

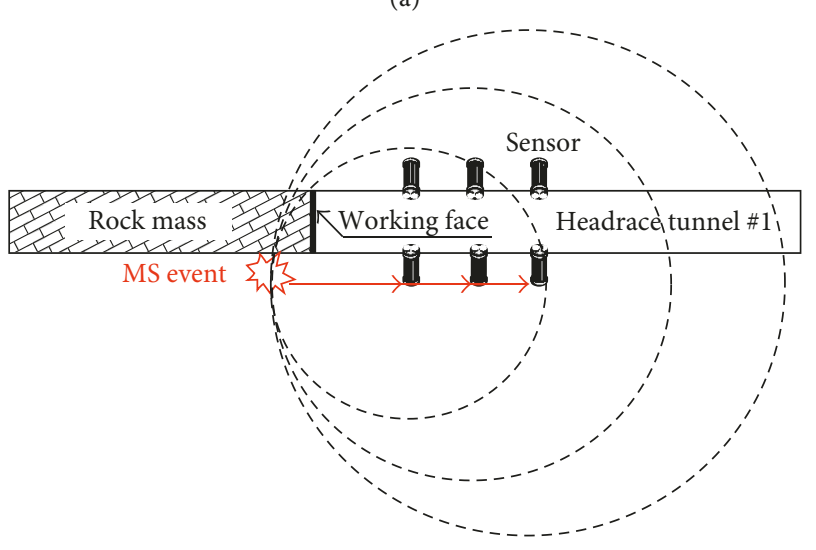

(b)

FIgURE 10: (a) The layout scheme and (b) source location mode of the following sensor array. axis are relatively large. The MS events may distribute on a sphere because of the picking errors of their arrival time. However, the position accuracy of MS event clusters along the axis of the headrace tunnel \#1 monitored by the high-sensitivity and high-precision MS monitoring system can be still accepted to study the evolution and locations of rockbursts.

(ii) The neighbour sensor array: As shown in Figure 11 (a), this array takes advantage of the sidewall of the neighbour headrace tunnel \#2 to install the sensors. Then, the MS events induced by the TBM excavation in the headrace tunnel \#1 can be monitored. This array requires the advancement of the adjacent tunnel to be remarkably prior to that of the headrace tunnel \#1. This layout ensures that the MS devices could be installed and moved conveniently and the process is not affected by TBM advancing speed. Moreover, the staff and MS equipment are safer since they are further away from the excavation face. Last but not least, accelerometers can be installed in front of the excavation face resulting in an intersecting orientation mode shown in Figure 11(b). This mode has different propagation directions of MS waves generated by microcracking proved to be more accurate for source positioning compared to the tangent mode.

Both two sensor arrays can realize movable monitoring of the tunnel with the advancement of the TBM. The arrays need to be specially designed on the basis of the working conditions of excavation faces so that the sensor layout may be various. If possible, two arrays are recommended to work 


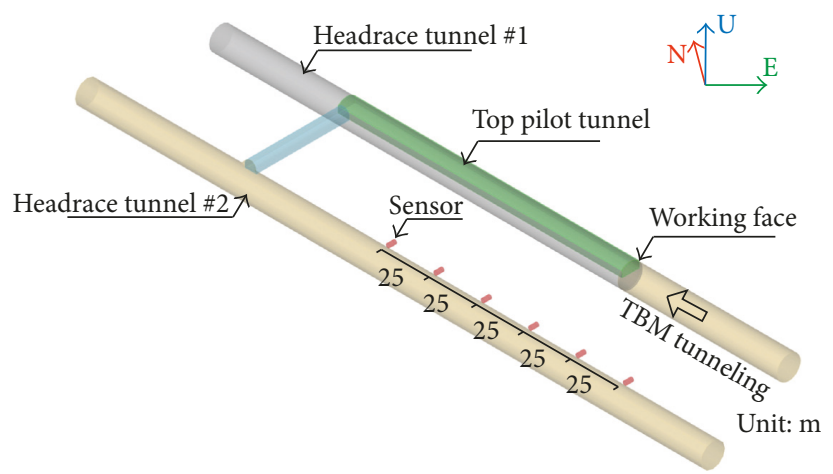

(a)

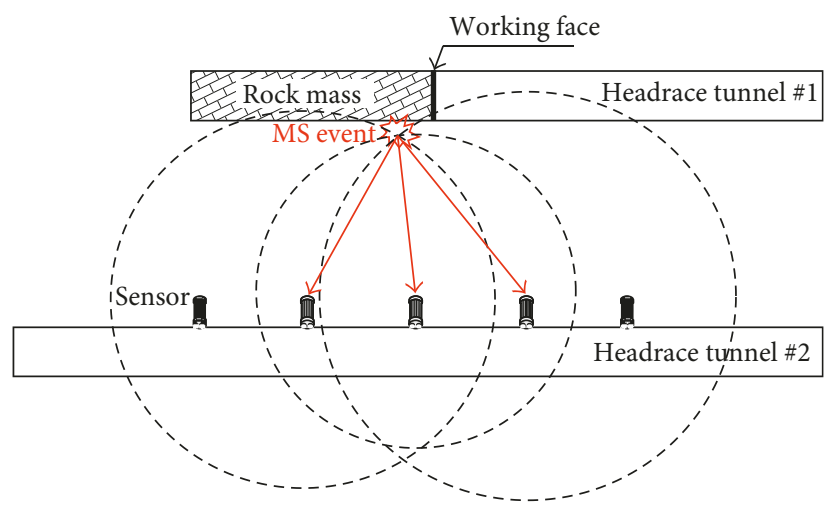

(b)

Figure 11: (a) The layout scheme and (b) source location mode of the neighbour sensor array.

synchronously for the sake of higher monitoring accuracy. If not, the latter sensor array is recommended for the sake of safer working conditions. In this study, the following sensor array was firstly considered to be installed in the TBM to monitor the MS events. Then, the neighbour sensor array was adopted when the working conditions are available in the adjacent tunnel.

For the installations in practice, the accelerometers shall be installed away from faults, and the distance between two sensors at the same elevation shall not be too large. The end surface of the accelerometer shall be as parallel as possible to the propagation direction of elastic waves generated by microcracking, making sure that the accelerometer could receive the effective microcracking signals. Meanwhile, in order to collect effective signals, the bolt resin had to be applied as a binder for the anchor bolt at the end surface of the accelerometer, so that the accelerometer clung to the borehole bottom. In addition, the borehole mouth was sealed by ploy foam to preliminarily filter out the external machinery noises.

4.3. Waveform Recognition and Noise Filtering. During the monitoring of MS events, a large number of signals originated from various sources were detected. It is really a tough task to distinguish the MS signals from the complex signals. Different types of signals such as electric current, knocking, rock drilling machine, TBM, ventilating fan, locomotive horn, blasting, MS event, and rockburst were recorded by MS monitoring system listed in Table 2 [35]. Based on wave features in the time domain and frequency domain, the waveform recognition was implemented, and the various undesired noise signals were filtered to obtain the signals of MS events and rockbursts. After that, source location and parameter calculation were carried out automatically by the data processing software. Source parameters, including source location, seismic moment, energy index, and spectral parameters, were available for the personnel to analyze the MS evolutions during the TBM tunneling through the top pilot tunnel in the headrace tunnel \#1.

\section{MS Monitoring Results and Discussions}

5.1. Spatial Distribution of MS Events. The MS monitoring system was installed and tested for the monitoring of the TBM excavation before May 20, 2010. The mileage of the top pilot tunnel ranged from chainage $11+976 \mathrm{~m}$ to chainage 12 $+125 \mathrm{~m}$ in the headrace tunnel \#1. Figure 12 depicts the MS events recorded when the TBM tunneled through the top pilot tunnel from southeast to northwest. MS events were mainly distributed at the two ends of the top pilot tunnel and few occurred in the top pilot tunnel section. Two concentrated zones are marked in Figure 12. One is located at chainage $12+125 \mathrm{~m}$ where the space between the southern end of top pilot tunnel and the excavation face of the remaining tunnel formed into a rock pillar. Energy release induced by the unloading excavation of the TBM took place in the rock pillar leading to a series of MS events. Several events with high energy were dispersedly distributed when 
TABLe 2: Acoustic waveforms encountered at the Jinping deep-buried tunnels [35].

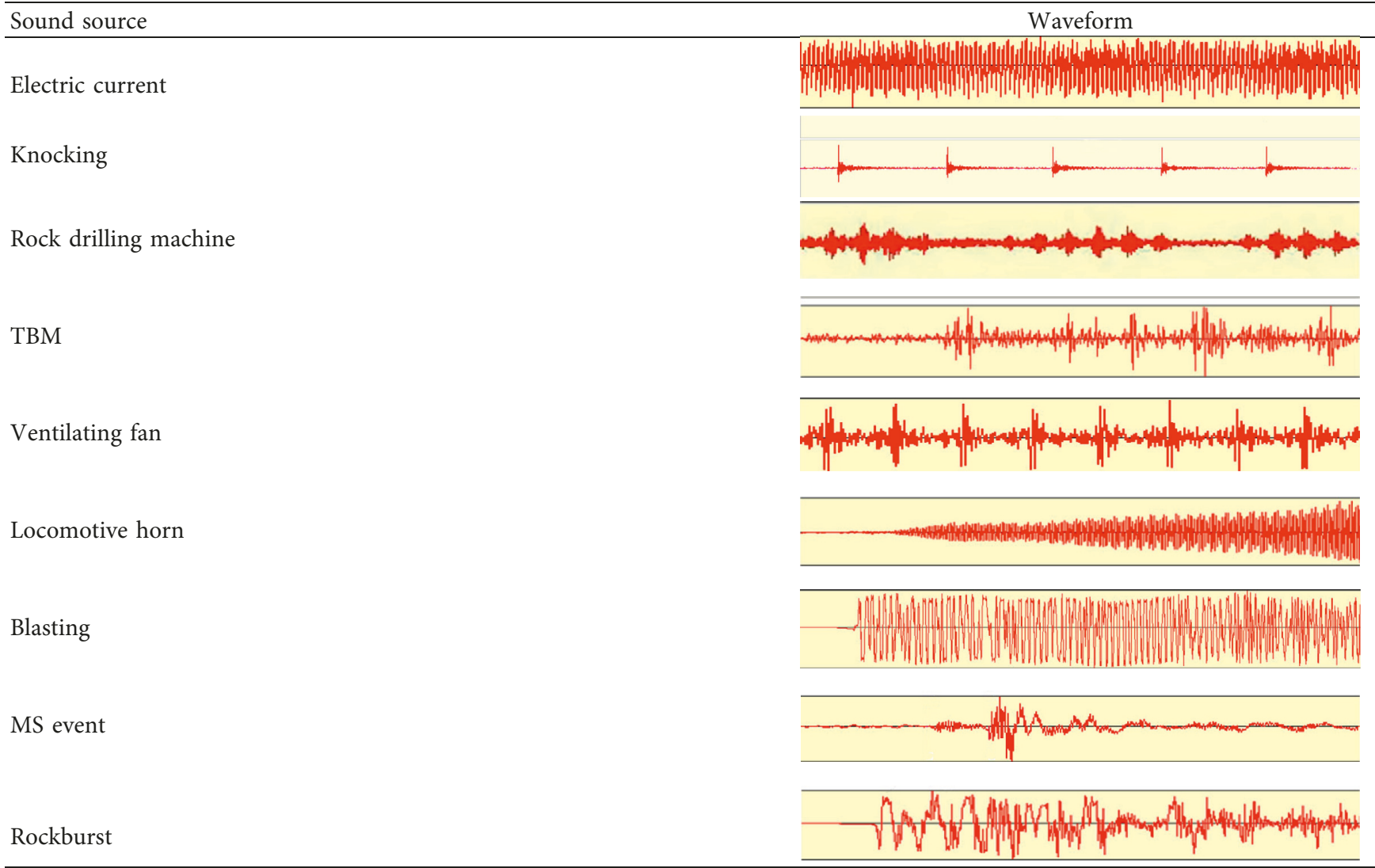

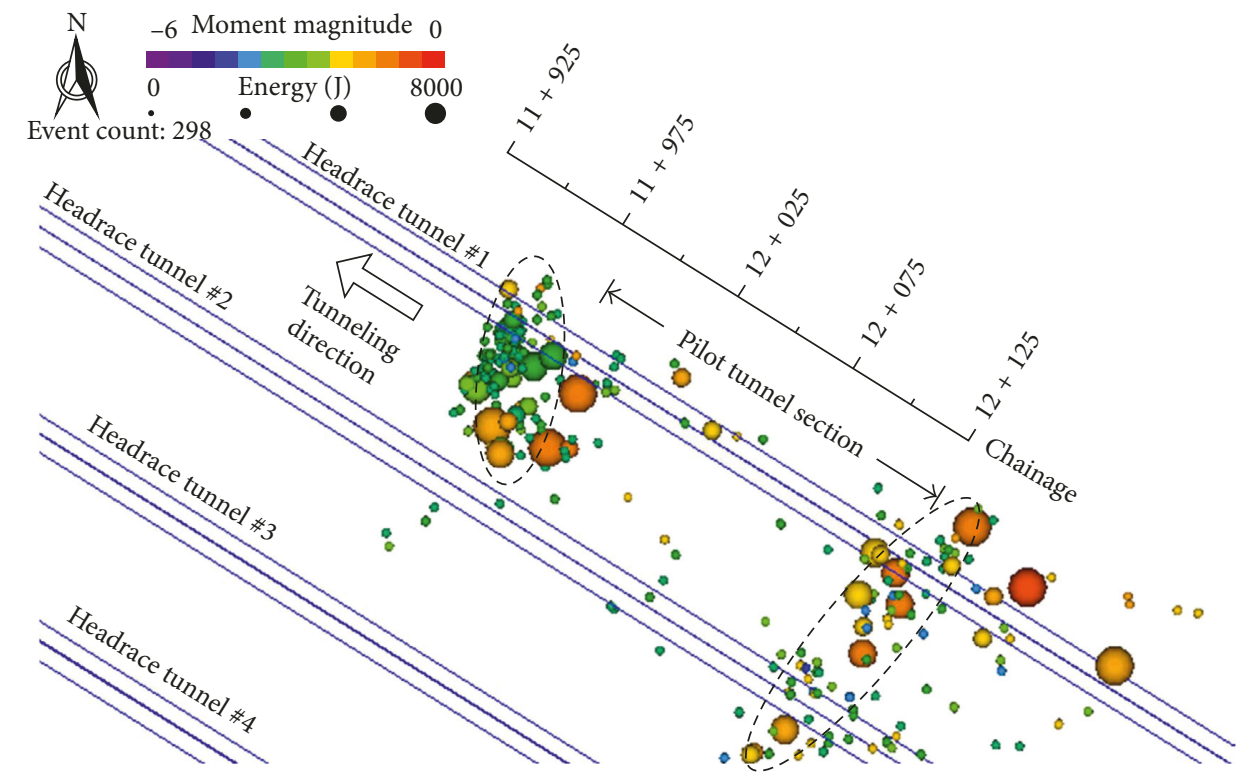

Figure 12: MS events recorded during TBM tunneling from 6 May to 17 June.

the TBM firstly tunneled across the southern end of the top pilot tunnel section. Locating at chainage $11+975 \mathrm{~m}$, the other zone is in northwest of the top pilot tunnel which was featured by the occurrence of more MS events with some of them having large energy.
5.2. Energy Changes during the TBM Tunneling. Figure 13 shows the density of the MS events during the TBM passing through the top pilot tunnel section. Generally, with the increase of the MS event density, the MS energy goes up, which indicates that the energy release of the surrounding 


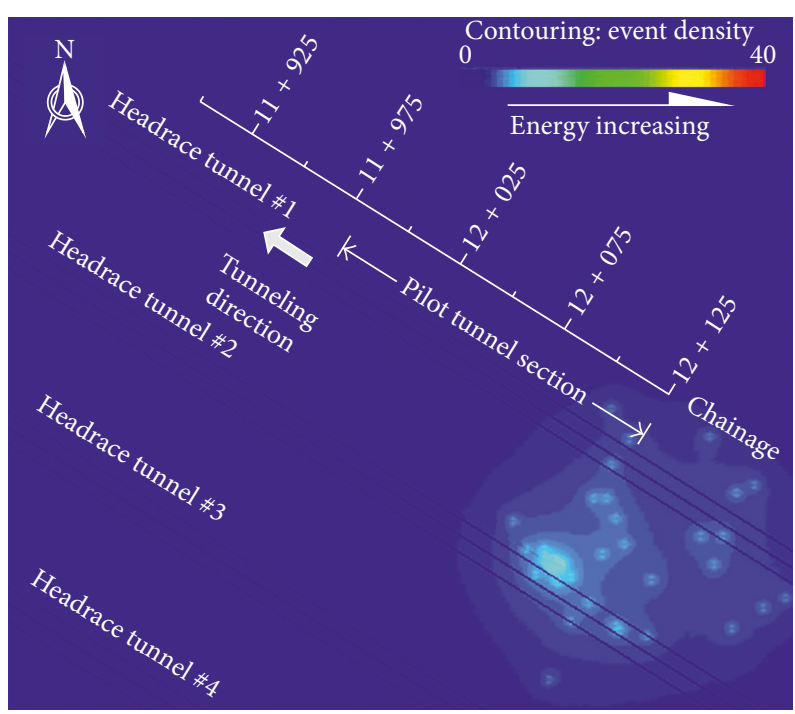

(a)

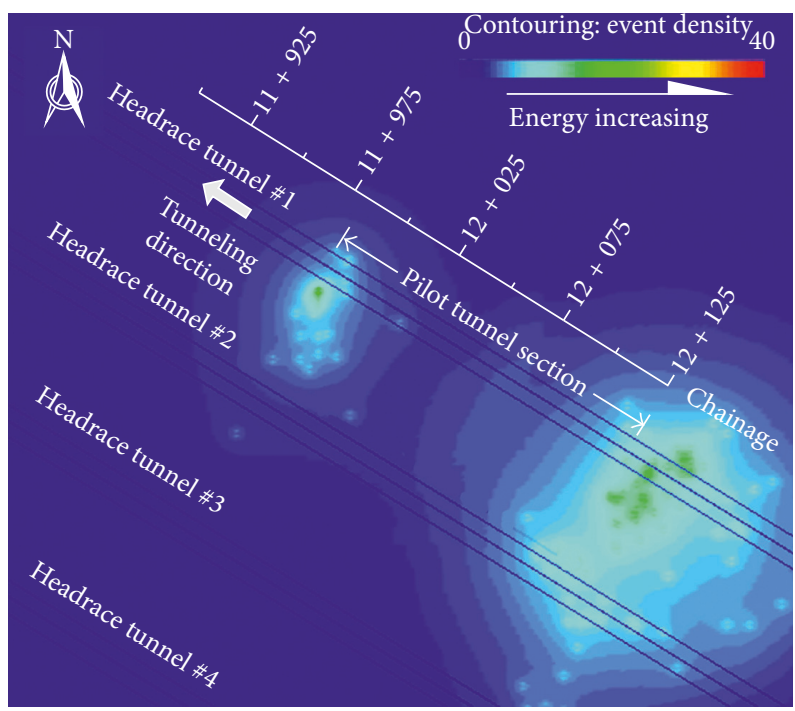

(c)

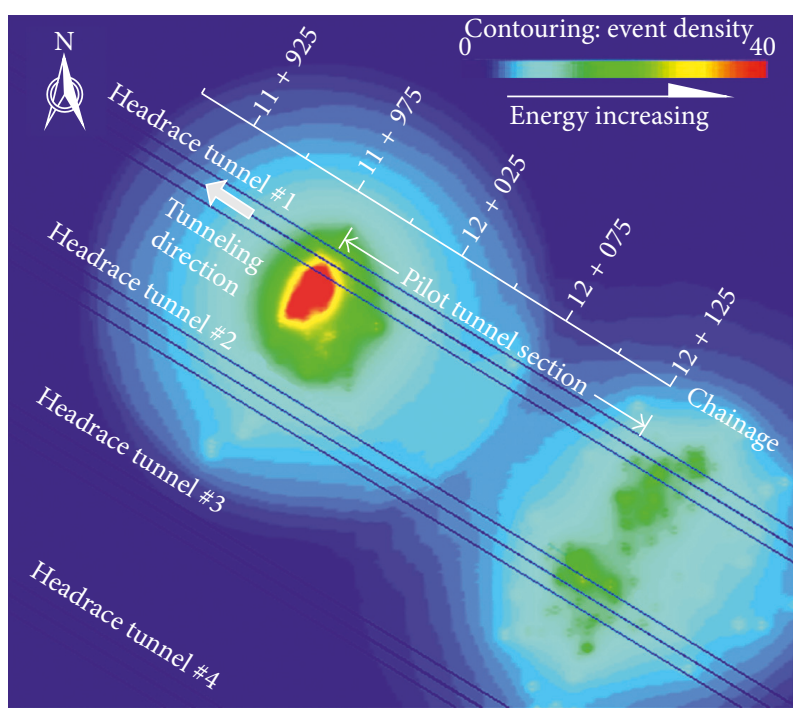

(e)

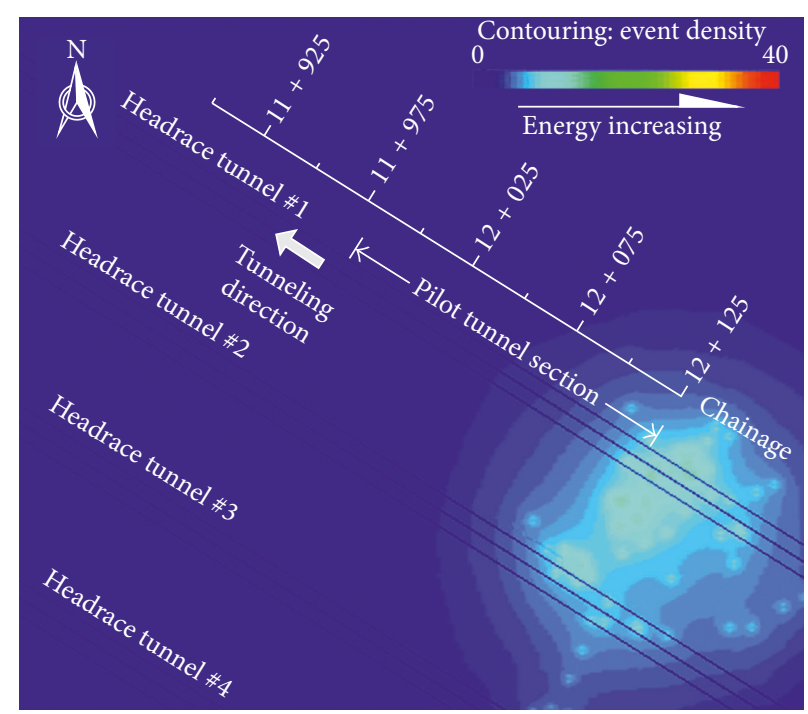

(b)

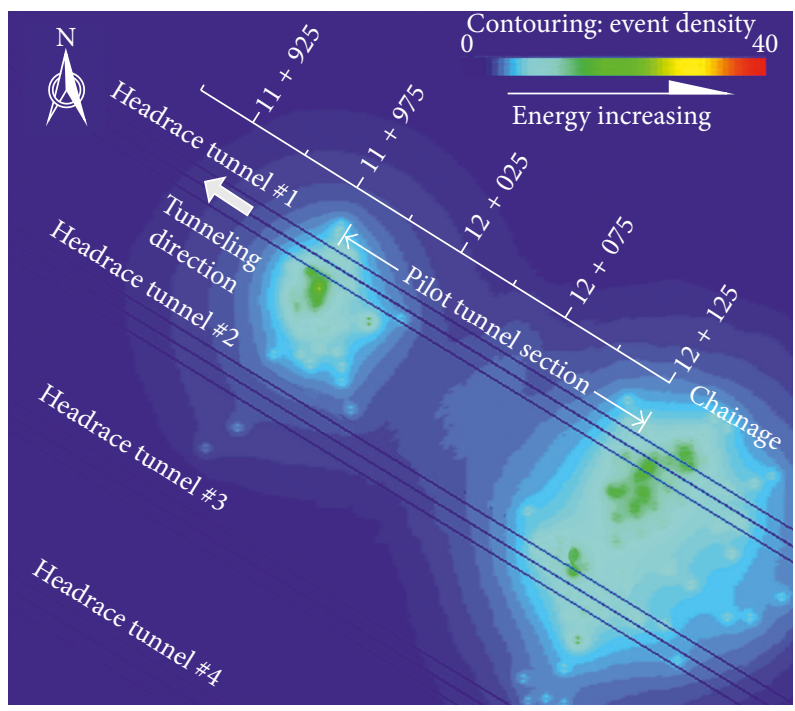

(d)

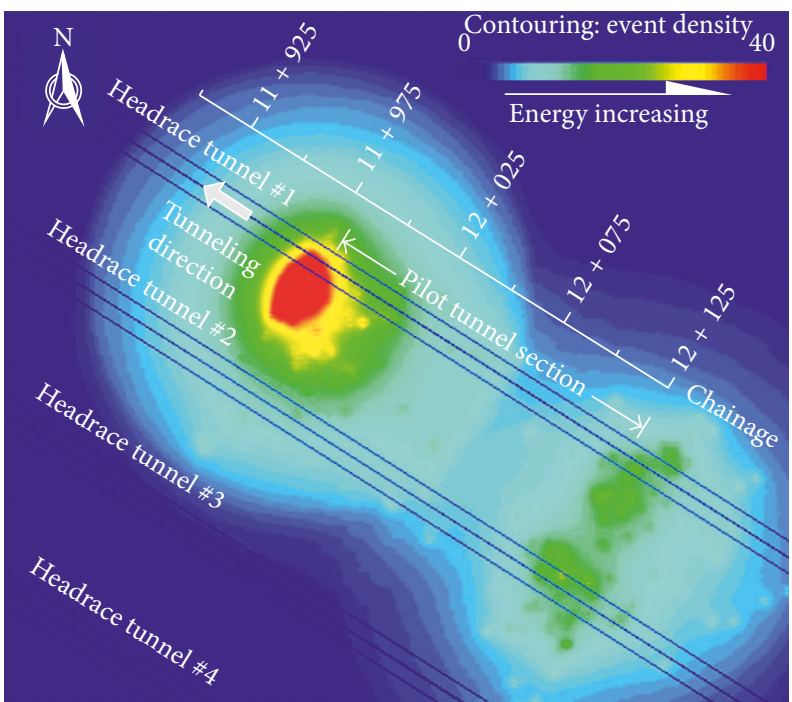

(f)

Figure 13: The accumulative density nephogram of MS events during the TBM excavation. (a) 21 May, 2010. (b) 24 May, 2010. (c) 27 May, 2010. (d) 30 May, 2010. (e) 5 June, 2010. (f) 17 June, 2010. 
rock masses induced by excavating rises [50]. On 21 May, 2010, the TBM advanced to the southern end of the top pilot tunnel, MS events triggered by tunneling were mainly distributed at chainage $12+125 \mathrm{~m}$ of the headrace tunnel \#1 and extended to the headrace tunnel \#2 (Figure 13(a)). With further advance of TBM, the excavation face moved forward and more MS events occurred near the southern end. Correspondingly, MS energy accumulated continuously, and a relatively high-energy release zone was formed (Figure 13(b)). Up to 27 May, MS events accumulated near the northern end of the top pilot tunnel, and energy transference of the surrounding rock masses from chainage $12+125 \mathrm{~m}$ to chainage $11+980 \mathrm{~m}$ of headrace tunnel \#1 was trigged by the advancement of TBM shown in Figure 13(c). However, no obvious increase in the MS events' density was observed near the southern end of the top pilot tunnel afterwards, reflecting that the energy here had been fully released and the high-energy release zone had shifted to the northern end of the top pilot tunnel at chainage $11+980 \mathrm{~m}$ (Figure 13(d)). As shown in Figures 13(e)-13(f), MS events concentrated at the northern end of the top pilot tunnel rapidly. Energy accumulation and energy release occurred in the tunnel rock masses at chainage $11+975 \mathrm{~m}$, and the high energy release zone tended to transfer along the direction of the TBM advancement. Due to rapid TBM advance, highenergy release zones formed at the northern end and in front of the top pilot tunnel. Potential rockburst zones formed in the range within $30 \mathrm{~m}$ in front of the excavation face according to the occurrence mechanism of rockbursts in headrace tunnel \#1 [46]. Finally, a moderate rockburst occurred near chainage $11+935 \mathrm{~m}$ that is in front of the top pilot tunnel of the headrace tunnel $\# 1$, and the on-site photos are shown in Figure 14. From the prospective of energy changes, the surrounding rock masses of in deep tunnels go through a process of energy accumulation, energy release, and energy transference during the TBM tunneling. In the meantime, the evolution of a rockburst is a process of energy accumulation, energy release, and the occurrence of the rockburst.

5.3. Assessment of the Top Pilot Tunnel to Control the Rockburst. During the TBM tunneling through the top pilot tunnel, MS events were mainly distributed at the two ends of the top pilot tunnel. Energy accumulation and energy release of the tunnel rock masses induced by the TBM tunneling took place at chainage $11+975 \mathrm{~m}$ and chainage $12+125 \mathrm{~m}$ of the headrace tunnel \#1. Moreover, with the advancement of the TBM, high-energy release zone transferred to the area northwest of the top pilot tunnel along the headrace tunnel axis. However, only a few MS events occurred in the top pilot tunnel section of the headrace tunnel \#1 reflecting that the high energy in this section had been released through excavating the top pilot tunnel. The potential rockburst zone had transferred to the section in front of the TBM working face which is out of the top pilot tunnel section. Consequently, no rockbursts caused by the TBM advancing through the top pilot tunnel were encountered. The top pilot tunnel method works effectively in the reduction of rockburst risks. This can be verified from the energy release rates

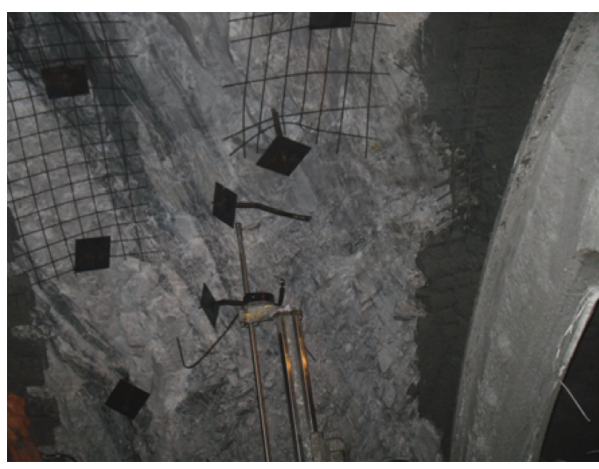

(a)

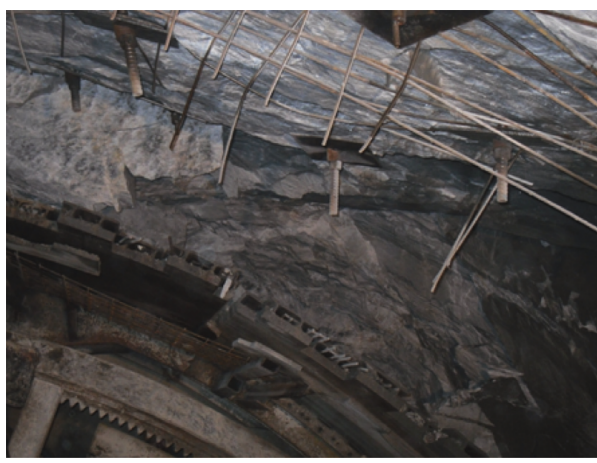

(b)

FIGURE 14: On-site photos showing moderate rockburst damage (taken on 6 July, 2010).

TABle 3: Energy release rates of different excavation steps of the headrace tunnel [51].

\begin{tabular}{lc}
\hline Excavation scheme & Energy release rate $\left(\mathrm{MJ} / \mathrm{m}^{3}\right)$ \\
\hline Top pilot tunnel excavation & 0.100 \\
Remaining tunnel excavation & 0.042 \\
Full-face excavation by the TBM & 0.096 \\
\hline
\end{tabular}

of top pilot tunnel and remaining tunnel listed in Table 3 computed by Fang et al. [51]. The energy release rate of the top pilot tunnel excavation is $0.1 \mathrm{MJ} / \mathrm{m}^{3}$ while the energy release rate of the remaining tunnel excavation significantly decreases to the value of $0.042 \mathrm{MJ} / \mathrm{m}^{3}$ with a reduction of $58 \%$. If the headrace tunnel was excavated directly by the TBM in full-face tunneling method, the energy release rate reaches $0.096 \mathrm{MJ} / \mathrm{m}^{3}$. Comparatively, the top pilot tunnel preconditioning method helps the energy release rate of remaining tunnel excavation by the TBM fall off with a percentage of $56 \%$. Above all, the risks of rockbursts in the headrace tunnel \#1 have been well controlled by excavating the top pilot tunnel. It is worth noting that the top pilot tunnel method cannot avoid the occurrence of rockbursts and just helps reduce and transfer the risk of the rockburst as revealed by the transference of the high-energy zone in the headrace tunnel \#1. In other words, though the top pilot tunnel was excavated in advance, deep tunnels with high risks of rockbursts may encounter rockburst. Hence, necessary MS monitoring, careful excavation, and immediate 
support are recommended for the similar deep tunnel engineering.

\section{Conclusions}

In this study, a movable integrated system was established to monitor MS events and rockbursts in real-time when the TBM excavated the headrace tunnel \#1 at the Jinping II hydropower station. Two schemes of sensor arrays, called the following sensor array and the neighbour sensor array, were proposed to adjust the sensor locations with the TBM advancing. The spatial patterns of the MS events and energy changes in the surrounding rock masses during the TBM tunneling through the top pilot tunnel section of the headrace tunnel \#1 were revealed. In the meantime, the evolution process of a rockburst occurred in front of the TBM excavation face was discussed, and the performance of the top pilot tunnel method on the reduction the rockburst risks in the headrace tunnel \#1 was assessed. It is found that the following sensor array leads to a tangent orientation mode for source location while the neighbour sensor array produces an intersecting orientation mode for source positioning with the latter one more accurate and recommended for field application if possible. When the TBM tunneled through the top pilot tunnel, MS events were mainly distributed at the two ends of the top pilot tunnel and few appeared inside the top pilot tunnel section. Energy accumulation and energy release firstly occurred in the surrounding rock masses at the southern end of the top pilot tunnel. Then, energy transference of the rock masses took place from the southern end to northwest of the top pilot tunnel giving rise to the occurrence of a moderate rockburst about $30 \mathrm{~m}$ in front of the tunnel. In other words, the top pilot tunnel method really works in reducing the risks of rockbursts in the TBM tunneling of the deep tunnels considering that no rockbursts happened when the TBM excavated through the top pilot tunnel section.

\section{Data Availability}

The detailed data of MS monitoring system are available in the concluding report of the MS monitoring service for the headrace tunnels and drainage tunnel at the Jinping II hydropower station which is completed by Dalian University of Technology and Mechsoft (Dalian) Co., Ltd.

\section{Conflicts of Interest}

The authors declare no conflicts of interest.

\section{Acknowledgments}

This research program was financially supported by the National Natural Science Foundation of China (nos. 51774064, 51504233, and 51774184) and the Fundamental Research Funds for the Central Universities (no. DUT17RC (3)015). The authors thank the colleagues at the Jinping II hydropower station for their valuable contributions to the project.

\section{References}

[1] S. Dudhani, A. K. Sinha, and S. S. Inamdar, "Assessment of small hydropower potential using remote sensing data for sustainable development in India," Energy Policy, vol. 34, no. 17, pp. 3195-3205, 2006.

[2] S. Guo, J. Chen, Y. Li, P. Liu, and T. Li, "Joint operation of the multi-reservoir system of the Three Gorges and the Qingjiang cascade reservoirs," Energies, vol. 4, no. 7, pp. 1036-1050, 2011.

[3] C. Jia, Y. Li, M. Lian, and X. Zhou, "Jointed surrounding rock mass stability analysis on an underground cavern in a hydropower station based on the extended key block theory," Energies, vol. 10, no. 4, p. 563, 2017.

[4] S. Wu, M. Shen, and W. Jian, "Jinping hydropower project: main technical issues on engineering geology and rock mechanics," Bulletin of Engineering Geology and the Environment, vol. 69, no. 3, pp. 343-351, 2010.

[5] S. Li, X. Feng, Z. Li, C. Zhang, and B. Chen, "Evolution of fractures in the excavation damaged zone of a deeply buried tunnel during TBM construction," International Journal of Rock Mechanics and Mining Sciences, vol. 55, pp. 125-138, 2012.

[6] S. Wu, G. Wang, J. Xu, and J. Wang, "Research on TBM typeselection and key construction technology for Jinping II hydropower station," Chinese Journal of Mechanical Engineering, vol. 27, no. 10, pp. 2000-2009, 2008.

[7] W. Cheng, W. Wang, S. Huang, and P. Ma, "Acoustic emission monitoring of rockbursts during TBM-excavated headrace tunneling at Jinping II hydropower station," Journal of Rock Mechanics and Geotechnical Engineering, vol. 5, no. 6, pp. 486-494, 2013.

[8] S. Li, X. Feng, Z. Li et al, "In situ experiments on width and evolution characteristics of excavation damaged zone in deeply buried tunnels," Science China Technological Sciences, vol. 54, no. S1, pp. 167-174, 2011.

[9] P. Lin, H. Liu, and W. Zhou, "Experimental study on failure behaviour of deep tunnels under high in-situ stresses," Tunnelling and Underground Space Technology, vol. 46, pp. 28-45, 2015.

[10] C. Zhang, X. Feng, H. Zhou, S. Qiu, and W. Wu, "Case histories of four extremely intense rockbursts in deep tunnels," Rock Mechanics and Rock Engineering, vol. 45, no. 3, pp. 275-288, 2012.

[11] Z. Huang, C. Tang, M. A. Tianhui, and L. Tang, "Numerical test investigation on unloading rockburst process," Chinese Journal of Mechanical Engineering, vol. 30, pp. 3120-3128, 2011.

[12] Q. Yu, C. A. Tang, L. C. Li, H. Li, and G. W. Cheng, "Nucleation process of rockbursts based on microseismic monitoring of deep-buried tunnels for Jinping II hydropower station," Chinese Journal of Geotechnical Engineering, vol. 36, no. 12, pp. 2315-2322, 2014.

[13] T. Li, C. Ma, M. Zhu, L. Meng, and G. Chen, "Geomechanical types and mechanical analyses of rockbursts," Engineering Geology, vol. 222, pp. 72-83, 2017.

[14] D. D. Bolstad, "Rockburst control research by the US Bureau of Mine," in Proceedings of the 2nd International Symposium on Rockbursts and Seismicity in Mines, pp. 8-10, Minneapolis, MN, USA, June 1988.

[15] P. K. Kaiser, Canadian Rockburst Support Handbook, Geomechanics Research Centre, Sudbury, ON, Canada, 1996

[16] F. Essrich, "Quantitative rockburst hazard assessment at Elandsrand Gold Mine," Journal of the South African Institute of Mining and Metallurgy, vol. 97, no. 7, pp. 319-324, 1997. 
[17] Y. Tan, "Characteristics of rockburst and structural effect on rock mass," Science in China Series B-Chemistry, vol. 9, no. 9, pp. 985-991, 1992.

[18] H. Xie and W. G. Pariseau, "Fractal character and mechanism of rock bursts," International Journal of Rock Mechanics and Mining Sciences \& Geomechanics Abstracts, vol. 30, no. 4, pp. 343-350, 1993.

[19] W. D. Ortlepp and T. R. Stacey, "Rockburst mechanisms in tunnels and shafts," Tunnelling and Underground Space Technology, vol. 9, no. 1, pp. 59-65, 1994.

[20] J. Zhang and B. Fu, "Rockburst and its criteria and control," Chinese Journal of Mechanical Engineering, vol. 27, no. 10, pp. 2034-2042, 2008.

[21] X. Feng, B. Chen, S. Li et al., "Studies on the evolution process of rockbursts in deep tunnels," Journal of Rock Mechanics and Geotechnical Engineering, vol. 4, no. 4, pp. 289-295, 2012.

[22] M. Cai, "Principles of rock support in burst-prone ground," Tunnelling and Underground Space Technology, vol. 36, pp. 46-56, 2013.

[23] P. Fan, M. Wang, S. Yue, and C. Shi, "Review on the evolution law, mechanics and prevention of strain rockburst," Journal of Wuhan University of Technology, vol. 35, no. 4, pp. 96-101, 2013.

[24] G. Chen, T. Li, G. Zhang, H. Yin, and H. Zhang, "Temperature effect of rock burst for hard rock in deep-buried tunnel," Natural Hazards, vol. 72, no. 2, pp. 915-926, 2014.

[25] G. Chen, T. Li, W. Wang, F. Guo, and H. Yin, "Characterization of the brittleness of hard rock at different temperatures using uniaxial compression tests," Geomechanics and Engineering, vol. 13, no. 1, pp. 63-77, 2017.

[26] Z. Xu, P. Wu, S. Wang, and Z. Tang, "Analysis of energy released in process of rock-burst," Journal of Natural Disaster Science, vol. 12, no. 3, pp. 104-110, 2003.

[27] H. P. Xie, Y. Ju, L. Y. Li, and R. D. Peng, "Energy mechanism of deformation and failure of rock masses," Chinese Journal of Rock Mechanics and Engineering, vol. 27, no. 9, pp. 1729-1740, 2008.

[28] M. Cai and D. Champaigne, "Development of a fully debonded cone bolt for rockburst support," in Proceedings of the International Seminar on Deep and High Stress Mining, pp. 329-342, Santiago, Chile, October 2010.

[29] M. M. Murphy, E. C. Westman, A. Iannacchione, and T. M. Barczak, "Relationship between radiated seismic energy and explosive pressure for controlled methane and coal dust explosions in an underground mine," Tunnelling and Underground Space Technology, vol. 28, no. 1, pp. 278-286, 2012.

[30] Q. Jiang, G. S. Su, X. T. Feng, J. Cui, P. Z. Pan, and J. Q. Jiang, "Observation of rock fragment ejection in post-failure response," International Journal of Rock Mechanics and Mining Sciences, vol. 74, pp. 30-37, 2015.

[31] Y. X. Xiao, X. T. Feng, J. A. Hudson, B.-R. Chen, G. L. Feng, and J. P. Liu, "ISRM suggested method for in situ microseismic monitoring of the fracturing process in rock masses," Rock Mechanics and Rock Engineering, vol. 49, no. 1, pp. 343-369, 2016.

[32] C. Tang, J. Wang, and J. Zhang, "Preliminary engineering application of microseismic monitoring technique to rockburst prediction in tunneling of Jinping II project," Journal of Rock Mechanics and Geotechnical Engineering, vol. 2, no. 3, pp. 193-208, 2010.

[33] C.-P. Lu, L.-M. Dou, N. Zhang et al., "Microseismic frequency-spectrum evolutionary rule of rockburst triggered by roof fall," International Journal of Rock Mechanics and Mining Sciences, vol. 64, pp. 6-16, 2013.
[34] B. R. Chen, X. T. Feng, Q. P. Li, R. Z. Luo, and S. J. Li, "Rock burst intensity classification based on the radiated energy with damage intensity at Jinping II hydropower station, China," Rock Mechanics and Rock Engineering, vol. 48, no. 1, pp. 289-303, 2013.

[35] T. H. Ma, C. A. Tang, L. X. Tang, W. D. Zhang, and L. Wang, "Rockburst characteristics and microseismic monitoring of deep-buried tunnels for Jinping II Hydropower Station," Tunnelling and Underground Space Technology, vol. 49, pp. 345-368, 2015.

[36] G. L. Feng, X. T. Feng, B. R. Chen, and Y. X. Xiao, "Microseismic sequences associated with rockbursts in the tunnels of the Jinping II hydropower station," International Journal of Rock Mechanics and Mining Sciences, vol. 80, pp. 89-100, 2015.

[37] Y. X. Xiao, X. T. Feng, S. J. Li, G. L. Feng, and Y. Yu, "Rock mass failure mechanisms during the evolution process of rockbursts in tunnels," International Journal of Rock Mechanics and Mining Sciences, vol. 83, pp. 174-181, 2016.

[38] P. Konicek, K. Soucek, L. Stas, and R. Singh, "Long-hole destress blasting for rockburst control during deep underground coal mining," International Journal of Rock Mechanics and Mining Sciences, vol. 61, pp. 141-153, 2013.

[39] A. A. Eremenko, V. A. Eremenko, A. N. Aleksandrov, and V. N. Koltyshev, "Hands-on experience of safe and efficient ore mining in Siberia," J. Min. Sci., vol. 50, no. 5, pp. 878-891, 2014.

[40] G. F. Liu, X. T. Feng, G. L. Feng, B. R. Chen, D. F. Chen, and S. Q. Duan, "A method for dynamic risk assessment and management of rockbursts in drill and blast tunnels," Rock Mechanics and Rock Engineering, vol. 49, no. 8, pp. 32573279, 2016.

[41] A. Wojtecki, M. J. Mendecki, and W. M. Zuberek, "The seismic source parameters of tremors provoked by destress blastings in coal seam," Journal of Mining Science, vol. 52, no. 2, pp. 258-264, 2016.

[42] L. Weng, L. Huang, A. Taheri, and X. Li, "Rockburst characteristics and numerical simulation based on a strain energy density index: a case study of a roadway in Linglong gold mine, China," Tunnelling and Underground Space Technology, vol. 69, pp. 223-232, 2017.

[43] C. Zhang, X. T. Feng, H. Zhou, S. Qiu, and W. Wu, "Rockmass damage development following two extremely intense rockbursts in deep tunnels at Jinping II hydropower station, southwestern China," Bulletin of Engineering Geology and the Environment, vol. 72, no. 2, pp. 237-247, 2013.

[44] C. Zhang, X. T. Feng, and H. Zhou, "Estimation of in situ stress along deep tunnels buried in complex geological conditions," International Journal of Rock Mechanics and Mining Sciences, vol. 52, no. 3, pp. 139-162, 2012.

[45] W. Zhang, T. Ma, C. Tang, and L. Tang, "Research on characteristics of rockburst and rules of microseismic monitoring at diversion tunnels in Jinping II Hydropower Station," Chinese Journal of Mechanical Engineering, vol. 33, no. 2, pp. 339-348, 2014.

[46] S. Wu, J. Zhou, B. Chen, and M. Huang, "Effect of excavation schemes of TBM on risk of rock burst of long tunnels at Jinping II Hydropower Station," Chinese Journal of Mechanical Engineering, vol. 34, no. 4, pp. 728-734, 2015.

[47] B. Chen, X. Feng, X. Zeng et al., "Real-time microseismic monitoring and its characteristic analysis during TBM tunneling in deep-buried tunnel," Chinese Journal of Mechanical Engineering, vol. 30, no. 2, pp. 275-283, 2011. 
[48] C. Zhang, X. Feng, H. Zhou, S. Qiu, and W. Wu, “A top pilot tunnel preconditioning method for the prevention of extremely intense rockbursts in deep tunnels excavated by TBMs," Rock Mechanics and Rock Engineering, vol. 45, no. 3, pp. 289-309, 2011.

[49] N. W. Xu, T. B. Li, F. Dai, R. Zhang, C. A. Tang, and L. X. Tang, "Microseismic monitoring of strainburst activities in deep tunnels at the Jinping II hydropower station, China," Rock Mechanics and Rock Engineering, vol. 49, no. 3, pp. 981-1000, 2015.

[50] D. Y. Zhuang, C. A. Tang, Z. Z. Liang, K. Ma, S. Y. Wang, and J. Z. Liang, "Effects of excavation unloading on the energyrelease patterns and stability of underground water-sealed oil storage caverns," Tunnelling and Underground Space Technology, vol. 61, pp. 122-133, 2017.

[51] D. Fang, N. Liu, C. Zhang, W. Chu, and X. Chen, "Rockburst risk control for large diameter TBM boring in high geostress region," Chinese Journal of Mechanical Engineering, vol. 32, no. 10, pp. 2100-2107, 2013. 


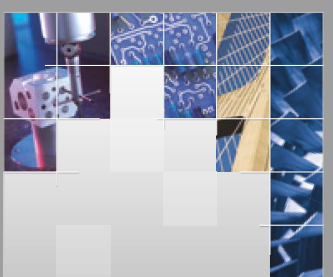

\section{Enfincering}
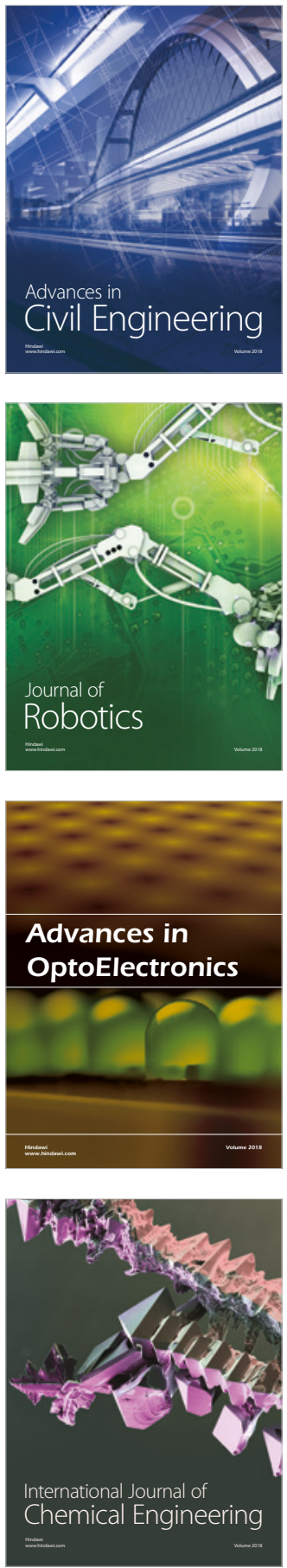

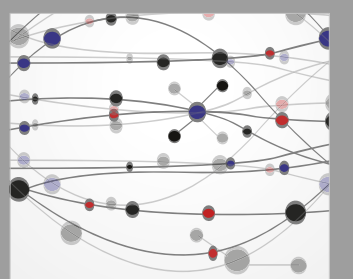

\section{Rotating \\ Machinery}

The Scientific World Journal

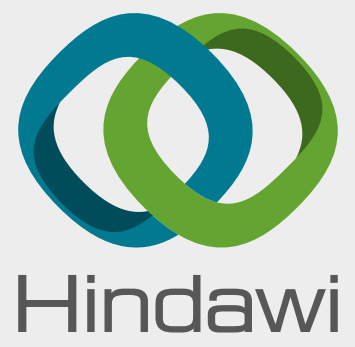

Submit your manuscripts at

www.hindawi.com
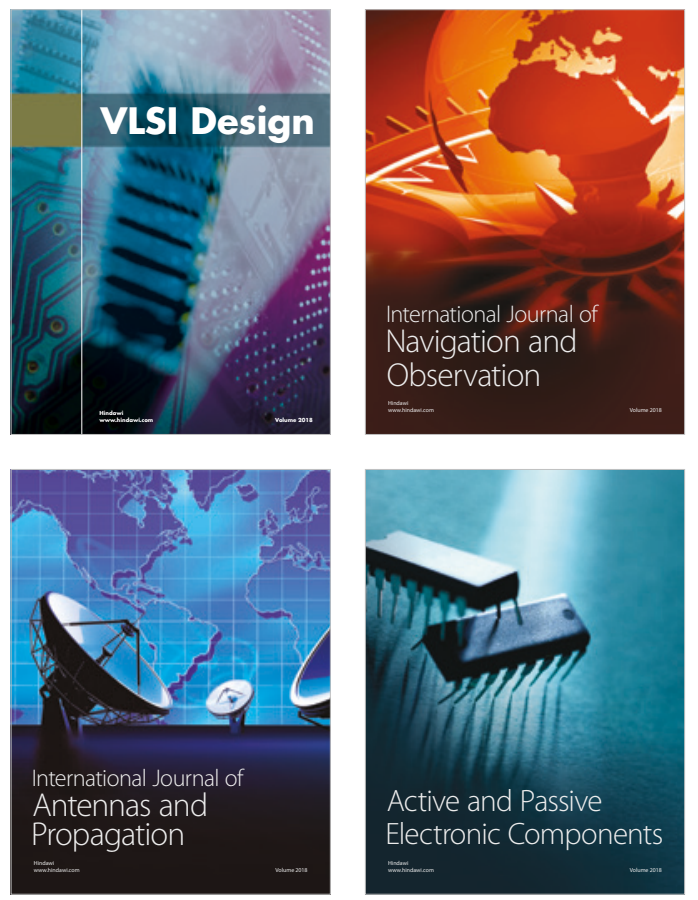
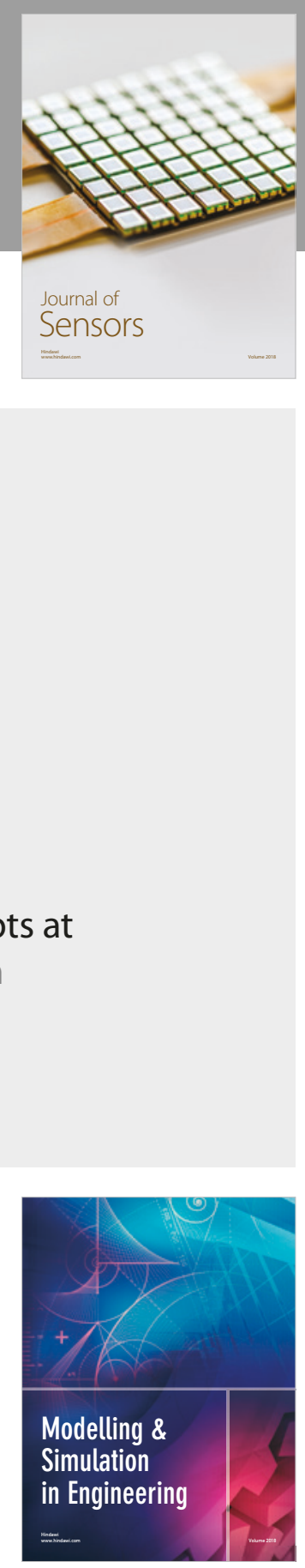

\section{Advances \\ Multimedia}
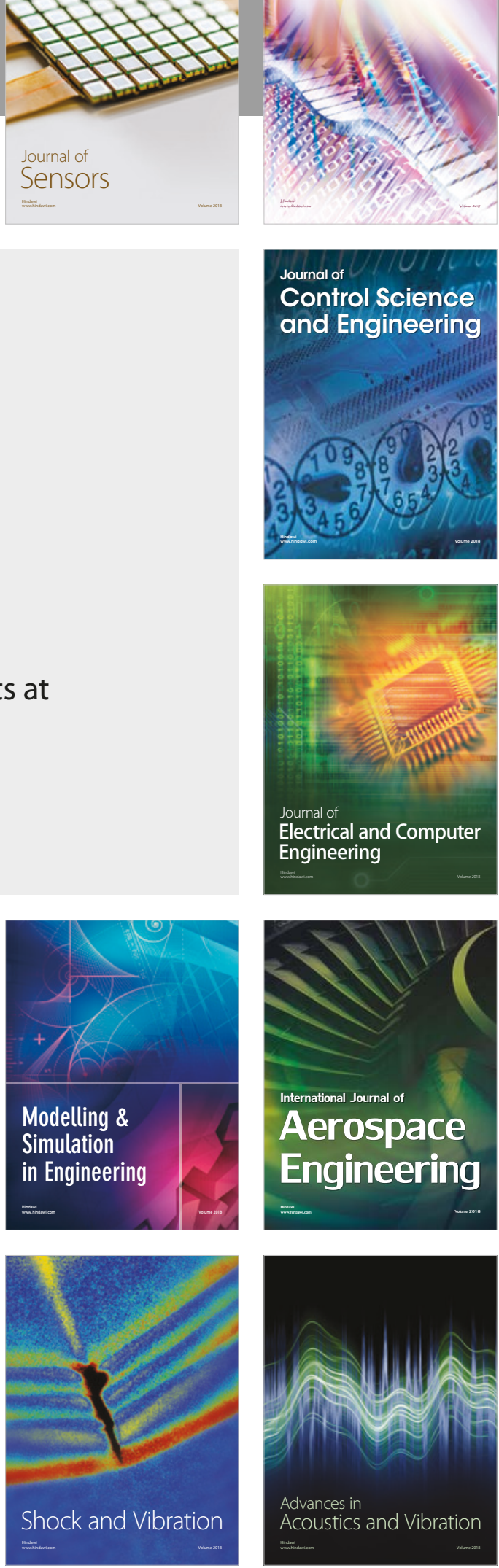